\title{
LINKS AMONG CORE ACTIVITIES OF HUMAN RESOURCE PERFORMANCE MANAGEMENT PROCESS
}

\author{
Andrea SAMOLEJOVÁ, Dominika KOŠTĚLOVÁ, Martin LAMPA \\ VSB - Technical University of Ostrava, Faculty of Materials Science and Technology, Czech Republic, EU, \\ andrea.samolejova@vsb.cz, dominika.kostelova.st@vsb.cz, martin.lampa@vsb.cz
}

https://doi.org/10.37904/metal.2019.771

\begin{abstract}
At the end of 2018, the unemployment rate in the Czech Republic was at its minimum for the last twenty years and the same applies within the framework of the EU member countries. Although being favourable in social terms, for companies this situation brings about large difficulties because they are unable to obtain qualified labour force, while costs connected with its finding and maintaining grow rapidly. For these reasons, company managers are compelled to pay an ever-increasing attention as to how the employees are utilised. Reciprocally to the growing costs in this manufacturing factor, they require also a growth in its outcome, in this case, the productivity of labour. The best and only complex instrument for the labour productivity growth is the systematic performance management (PM). In the sphere of the management of human resources, a number of activities are in place and some of them, in terms of labour productivity less valuable, divert the attention from the major personal actions. Therefore, this paper is focused to the delineation of core activities in the performance management and links among them in the sphere of metallurgy. In the sphere of metallurgy, there is a longstanding lack of qualified labour force, and hence the systematic performance management of human resources is of primary importance.
\end{abstract}

Keywords: HR, Performance Management, Personal Activities

\section{INTRODUCTION}

At present, the enterprises are under unprecedented pressures from their competitors and so they try to build and maintain their comparative advantage through the most important production factor - human resources [1]. Due to the minimum rate of unemployment, they are steadily more costly, so the managers intensify a pressure on their productivity. A productivity of labour can be achieved either by cost cutting or increasing the working outputs, i.e. the work performance. Due to the already mentioned fact that the wages must grow, in order to attract and stabilise the employees, then the managers have no other way than to search for options for increasing work performance of their employees within the systematic performance management. Improvements in the work performance represent a systematic approach for securing better work performance of people [1].

The metallurgical industry offers one of the most demanding working conditions [2]. Among other things, the employees are exposed to high temperatures, excessive dust, and physically demanding work tasks. During last twenty years, when mass redundancies from steel mills were common, the popularity of connected professions dropped so dramatically that some study branches had to be closed owing to the lack of applicants, and consequently qualified people in the manufacture of steel and castings are today simply missing at all work positions. Even in the era of high unemployment, the industrial enterprises had to struggle with the lack of interest of young people due to the demanding work, but today, when the lack of employees is evident across the whole economy their situation is even more difficult [3]. It happens frequently that young people, more than often with a minimum education level, come to the work, costs of their expensive medical examinations must be paid, and after few days or week at work, they terminate the employment, or go to a sick leave, or even - after few months' work - they report contracting an occupational disease. Therefore, the 
metallurgical companies have problems not only with the employee hiring, but also with their retention in the first place. Under such conditions, the HR managers must focus all their interest to the sphere of obtaining, motivating, and educating the employees in order to achieve the best possible work results and performance.

\section{WORK PERFORMANCE COMPONENTS}

The work performance can be defined as a result of a work activity within a certain period and under certain conditions [42]. The performance itself, i.e. the achievement of a certain level of meeting the assigned task, is influenced by many factors, particularly by the management style of senior executives or work conditions, such as workplace temperature, noise, or lighting [5].

The work performance is not only a human activity output but also the manner of its achievement. Apart from measurable work results of organisations, teams, and individuals, the modern definition of the work performance includes also behaviour of all involved persons [4]. Its indispensable part is also employee knowledge and his/her "soft skills", i.e. competences and abilities [4].

The work performance has three components: effort, professional qualifications, and work/organisational conditions created by the company [6]. For handling of the work performance, it is essential to understand that the employee motivation is the base for the work effort. The work performance magnitude can be expressed as the function of $V=f(S \times M)$, where $V$ is the performance level, quantity and quality. $M$ is the level of motivation, and $S$ expresses the employee capabilities. In order to achieve an optimum work performance, it is necessary to have all the three components - effort, professional qualifications, and work/organisational conditions - in a suitable ratio [7].

\section{BASIC PILLARS OF THE PERFORMANCE MANAGEMENT}

The following items rank among the four basic principles resulting in the efficient performance management:

1) It is the concern of line managers, and the HR units.

2) A stress must be laid to spreading and sharing of corporate objectives and values.

3) Every company must have its own "tailor-made" performance management.

4) It is not a concern of a selected group of employees only.

The performance management process of individual employees can be expressed as a continuous cycle. In its simplest concept, the employee performance is only evaluated (and even this is not often the case) rather than controlled. Such process then consists of only three phases [7]:

1) Planning of work tasks for the next monitored period.

2) Execution of work tasks by the employee.

3) One-time checks and evaluations of compliance with the job tasks at the period end (usually annually or biannually) without any links to the remuneration and development system. In addition, there is oneway communication from the superior to the evaluated subordinate, i.e. no feedbacks are in place.

However, other HR activities were gradually added into this concept and, in particular, into the performance management so that in the current stage of understanding the performance management, successful organisations are aware of the fact that the efficient performance management must suitably combine not only earlier included, but also other spheres connected with the management of human resources and with their motivation, in the first place. The employee motivation and consequently their work performance are very strongly influenced by the corporate culture as well as the work environment and other conditions that differentiate companies on the labour market, i.e. influencing the applicants' decisions where to accept the employment. 


\section{RECOMMENDATIONS FOR LINKS INSIDE THE PERFORMANCE MANAGEMENT PROCESS IN A METALLURGICAL ENTERPRISE}

The corporate culture in place as well as work conditions provided (including occupational safety and health) represent without exception the basis of all activities of human resources management and consequently the performance management [8]. Among other things, the corporate culture is shaped by the level of communication and feedbacks among the managers and their subordinates. From earlier surveys carried out by this paper author among metallurgical and cooperating manufacturing companies, significant shortcomings in communication with employees at the lowest positions were found. Very often, even basic information about their job descriptions, remuneration structure for their work, granted benefits or educational opportunities were not available to these employees. According to many enquiries made by this paper author, a majority of steel mill workers wants to know what is expected from them and how they can influence their remuneration through their performance. Basic pillars in the performance management process, the roles and mutual connections understandable to the ordinary employees, are as follows:

0) Acquiring and selection of employees (incl. job position analyses and descriptions)

1) Work performance planning

2) Work performance evaluation

3) Remunerations and motivations for the work performance

4) Education and personal development of employees.

The employee selection stage stands at the beginning of the performance management process, and its efficiency significantly influences the future performance of the employee, at least in terms of his/her adaptation and necessary initial training. The zero position is deliberately allotted to this stage because it concerns the employee usually only once within his/her employment in the relevant company. However, it is a very significant activity in the performance management process. If a company wants to achieve the maximum efficiency in this process, then they must have already in place a thoroughly elaborated system of creation, analysis, and description of work positions. In this complex approach to the performance management, the managers are aware that the fundamental prerequisite for efficient management of the work performance is a comprehensibly and realistically adjusted job description and, resulting out of this, the requirements laid on the executing persons. In expert terms, these two HR activities are called the job position description and specification. Just from them, both manager and personnel professional must start from the delineation of the relevant job ads for vacant positions. The performance management starts as early as in the process of employee obtaining and selection. If these two phases are underestimated or, as the case may be, not continuously updated, the whole performance management process would be considerably hindered. It is alarming that in the monitored metallurgical plants, descriptions and specifications of job positions were completely missing for a main part of blue-collar positions, and the managers relied only on daily setting of work tasks.

At the beginning of the defined period, it is necessary to make an agreement about the work plan for the next period. In this phase, a significant role is played by fact that not only the superior manager takes part in the preparation but in the first place, the relevant employee himself/herself. In this way the employee better understands his/her duties as well as all the conditions necessary for their meeting. That is the reason for forming such an agreement. In fact, the plan conditions set a yardstick for the whole performance management process. The working output, its evaluation, and remuneration will depend on them. Due to a lower level of qualifications of ordinary employees in the metallurgical business, it is essential that such conditions are realistic and easy to understand.

In the course of work performance itself, the direct superior support plays the key role, as well as his/her motivating management through immediate commendations, experienced couching, and continuous feedback. 
The achievement of goals of the performance management from the employee side will be enabled and accelerated by targeted motivations, including financial and non-financial remunerations. At this point, there were in the metallurgical business shortcomings in $95 \%$ of cases, where the workers did not know all the components forming their wage, while only $45 \%$ of inquired had (at best) a cursory glance about the benefits offered by their respective employers.

In order to have remuneration system motivating to higher working outputs, it must be necessarily interlinked with working output assessments. The monitored metallurgical plants have already tied up the wages to meeting of work norms (rates) and daily targets of employees, but this is not always easy to understand and/or suitably formed, and very often for groups only. Apart from the above-mentioned requirements for the rates, opportunities to set additional criteria for the working output are often neglected. In this way, it is not possible to remunerate, for instance, an extraordinary work effort, individual outputs, work behaviour, or creative approaches, i.e. the aspects that may significantly support and develop working outputs of evaluated persons.

At present, as already mentioned above, in the period of the high employment rate, it is not possible to find job applicants for the metallurgical plants whose professional competences correspond to the needs of vacant positions. Not only that the relevant training courses must be organised and financed by the metallurgical companies on their own and for many years already, but these investments are rather both costly and unreliable because new employees, particularly the younger ones, tend to run away after some time for more comfortable working conditions. However, even in the times, where the labour market was saturated with the job applicants, the companies must dynamically educate and develop their employees so that their respective skills and knowledge could response flexibly to the changing requirements of customers as regards the company goods and/or services. Therefore, it is necessary to engage systematically the educational and carrier-developing activities into the working output plans for every employee. In particular, the newly-hired employees, without necessary skills and knowledge, will be able to understand from these plans what all they have to catch up so they can execute their work duties correctly and - due to this - receive the maximum possible remuneration from the employer. At the same time, it is necessary to link the educational and carrierdeveloping plans to the remuneration system so that the employee is motivated from the outside - not only by his/her desire for the enhancement of his/her knowledge and skills.

\section{CONCLUSIONS}

Primarily, the performance management process and its improvements form a complex field involving all personnel activities. Unfortunately, the companies often overlook the ordinary employees and their ability level of understanding too sophisticated personnel information systems; they include so many data about the employees and what is offered to them, which frequently results in complicated and confusing situations, where the motivation elements of these costly and well-intentioned activities are disappearing. It is simple: the people can follow only the things they can understand. Therefore, the managers should verify the functionality and comprehensibility of motivating, evaluating, educating, and other HR activities for all the employees - not only for those at managerial and clerical positions.

It resulted, from a whole series of researches carried out by this paper author among the workers in metallurgical plants in the 2013/2018 period that it is essential, for their working output management and improvement, to give the employees a survey about their work duties, to update it regularly, and provide them with a connected scheme on the relevant remuneration so that they could understand the meaning of the working output evaluation and its link to the remuneration and education. For the ordinary employees it must be quite clear how they can increase higher financial and/or non-financial remunerations through increasing their work effort and how their further education can help them to improve their working output. 


\section{ACKNOWLEDGEMENTS}

The work was supported by the specific university research of the Ministry of Education, Youth and Sports of the Czech Republic in VSB - Technical University of Ostrava No. SP2019/62.

\section{REFERENCES}

[1] ROTHWELL, W. J., HOHNE, C. K., KING, S. B. Human Performance Improvement Building Practitioner Performance. London: Routledge, 2018. p. 254.

[2] SIKOROVÁ, A., I. ŠPIČKA a O. ZIMNÝ. The complex models of metallurgical aggregates. In Metal 2014: 23rd International Conference on Metallurgy and Materials. Ostrava: TANGER, 2014, pp. 1976-1981.

[3] MALINDZAK, D. APPLICATION OF LOGISTIC PRINCIPLES IN METALLURGICAL PRODUCTION. METALURGIJA. 2012. vol. 51, no. 3, pp. 345-348.

[4] PAUKNEROVÁ, D. a kol. Psychologie pro ekonomy a manažery. 2nd ed. Praha: Grada Publishing, 2006. p. 254.

[5] SMITHER, J. W., LONDON, M. Performance management: Putting research into action. San Francisco: John Wiley \& Sons, 2009. p. 500.

[6] KOCIÁNOVÁ, R. Personální činnosti a metody personální práce. Praha: Grada Publishing, 2010. p. 224.

[7] LAWLER, E. Effective human resource management: A global analysis. Stanford: Stanford University Press, 201. p. 216.

[8] SUCHACEK, J., BARANEK, P. Headquarters of Largest Enterprises in the Czech Republic from Regional Perspective. In Finance and the Performance of Firms in Science, Education, and Practice. Zlín: Tomas Bata University, 2011, pp. 469-478. 